\title{
Physicomechanical properties of nano-silica effect on geopolymer composites
}

\author{
Khater H M
}

\author{
Housing and Building National Research Centre (HBNRC), 87 El-Tahreer St., Dokki, Giza, P.O. Box 1770 \\ Cairo, Egypt. Tel: 00202-3761812-00201111686524. \\ Corresponding Author : hkhater4@yahoo.com
}

\begin{abstract}
Addition of $\mathrm{Nano}^{-\mathrm{SiO}_{2}}$ (NS) to geopolymer composites has been studied through measurement of compressive strengths, Fourier Transformer Infra-Red (FTIR) and X-ray diffraction (XRD) analysis. Alumino-silicate materials are coarse aggregate included waste concrete and demolished walls with its cementing binder, cement kiln dust (CKD) used and can possess a pronouncing activation for the geopolymer reaction resulting from the high alkali contents within. Materials prepared at water/binder ratios in a range of 0.30: 0.40 under curing of $40{ }^{\circ} \mathrm{C}$ and $100 \%$ R.H, while the used activator is sodium hydroxide in the ratio of $2 \mathrm{wt}$ \%. First, CKD is added in the ratio from 10 up to $50 \mathrm{wt}$., \%, and the demolished walls was varied depending on the used CKD content, while using constant ratio of waste concrete (40 wt., \%). Second step, depending on the optimum CKD ratio resulted from the first one ( $40 \mathrm{wt}$. \%), so the control geopolymer mix composed of CKD, demolished walls and waste concrete in the ratio (40:20:40, wt \%). NS partially replaced waste concrete by 1 up to $8 \%$. Results indicated that, compressive strengths of geopolymer mixes incorporating NS were obviously higher than those control one, especially at early ages and specially with $3 \% \mathrm{NS}$
\end{abstract}

Key words: Self-compacting concrete, Nanostructures, sol-gel growth, amorphous materials, composite materials, inorganic compounds.

\section{Introduction}

In this new century, the Nano-structured material technology developing at an astonishing speed and will be applied extensively with many materials. As known C-S-H gel in cement is a common building material where its main hydrate product is a natural Nano-structured material (Taylor, 1993; Richardson, 2000; Zhang et al., 2000). Whilst the addition of Nano-materials in cement and concrete can lead to an extra improvements in the nanostructure of hydrated building materials (Aiu and Huang, 2006). Unique physical and chemical properties of Nanomaterials lead to the development of more effective materials than ones which are currently available (Li et al., 2004).

Many researchers have applied slag; fly-ash and silica fume (SF) as a pozzolana for improving cement-based materials. It is well known that SF belongs to the category of highly pozzolanic materials because it consists essentially of non-crystalline silica with a high specific surface. However, the SF activity at early ages is somewhat low according to the literature (Mitchell et al., 1998; Papadakis, 1999). As the need for the development of alternative eco-friendly building materials, alkali-activated binders has been promoted by the growth of the building industry, the increased performance requirements placed upon materials, and the higher sustainability criteria applied in construction. Alkali-activated binders offers an attractive partial or complete substitution of Portland cement in the production of mortars and concretes, offering comparable performance and cost (Duxson et al., 2007-a) while reducing greenhouse gas emissions (Duxson et al., 2007-b). In the activation of aluminosilicate precursors; the most relevant characteristics related to the alkali activator are: the type of alkaline salt (usually silicate or hydroxide) (Van Jaarsveld and Van Deventer, 1999; Phair and Van Deventer, 2001; Fernández-Jiménez and Palomo, 2005); the method of addition of the alkaline component (as a solution or in solid-state) (Yang et al., 2008; Yang and Song, 2009; Hajimohammadi 2008) and the dosage of the alkali 
component, usually expressed as molar ratios considering the overall composition of the raw material. Additionally, it has been reported (Van Jaarsveld and Van Deventer, 1999; Duxson et al., 2007; Fernández-Jiménez, 2006) that the cationic alkali supplied by the alkaline solution influences the first stage of binder formation, consequently the mechanical performance of the final products. The alkali-activators conventionally used are sodium or potassium hydroxides, and/or sodium ( $\mathrm{Na}$ ) or potassium (K) silicates (Provis, 2009). Activation with K-containing solutions leads often to an increased compressive strength development as compared with Nacontaining solutions, where the size and charge density of the alkali cation play an important role in controlling the rate and extent of condensation during the polycondensation or crystallization process (McCormick and Bell, 1989), however, these effects are also dependent on the chemical and physical nature of the solid precursor used (Phair and Van Deventer, 2001).

Calcium hydroxide effect on the mechanical as well as microstructural characteristics of alkaline activated geopolymer alumino-silicates wastes produced from demolition works were investigated by Khater (2012), where calcium compound addition improve the mechanical and microstructural properties with hydrated lime up to $10 \mathrm{wt}$., $\%$ for water cured specimens under ambient temperature, while it slightly decreases for curing at $100 \% \mathrm{R} . \mathrm{H}$ at $40^{\circ} \mathrm{C}$. The effect of SF addition on properties of geopolymer materials produced from alkaline activated metakaolin and demolished waste concrete has been studied by Khater (2013-b), Results indicated that compressive strengths of geopolymer mixes incorporating SF increases up to 7\% substitution and then decreases up to $10 \%$ but still higher than the control mix. On the other hand, Cement kiln dust (CKD) which is an industrial waste from cement production has relatively high alkaline content which is predominant factored preventing its recycling in cement manufacture. However, these high alkalis lie in CKD could provide the necessary environment required for geopolymer activate depending on water-soluble alkalis and sulfate compounds. Utilization of CKD with its high alkali content in the activation of geopolymer specimens to create nonconventional cementitious binders was investigated by Khater (2013-a).

Based on this background, the aim of this paper is to study the effect of nano-silica addition on the physico-mechanical characteristics of the resulting geopolymer materials produced from construction and demolition wastes producing cementless materials that can be applied in many building applications. Testing of the resulting geopolymer product is studied by XRD, FTIR, compressive strength testing and drying shrinkage are conducted on pastes of Geopolymer based sample, in order to generate a better understanding of the effect of the NS on the behavior of Geopolymerization reaction.

\section{Experimental procedures}

\subsection{Materials}

Alumino silicate materials used in this investigation are demolished walls with its cementing binder as well as coarse aggregate included waste concrete both well grinded and passing a sieve of $90 \mu \mathrm{m}$ and sourced from 6th October landfills, Egypt. Cement kiln dust (CKD) which is a fine, highly alkaline powder produced from cement manufacture sourced from Helwan Cement Factory, Cairo, Egypt. Materials, which used in this investigation, were characterized by means of chemical analysis as represented in Table 1. Mineralogical characterization was done using XRD analysis, showing that demolished walls composed of quartz, calcite and portlandite (from cement mortar hydration) in a decreasing order. Coarse aggregate included waste concrete has a major content of quartz and little calcite content, CKD pattern depicts that it is composed of calcite, anhydrite, lime and a minor content from sylvite as represented in Figure 1. NS used in this investigation is a synthetic product with spherical particles in the range of 8-18 nm and 240 $\mathrm{m}^{2} / \mathrm{g}$ blain fineness imported from Sigma-Aldrich (Germany). The chemical analysis showed that it consists mainly of pure silica, 99\%, while its XRD pattern (Figure 1) shows that nanosilica is mostly composed of amorphous quartz. The physical properties of NS are given in Table 2. Laser particle size distribution pattern of NS indicate that its crystallinity is of an average particle size of $60 \mathrm{~nm}$. 
Table 1. Chemical properties of binders.

\begin{tabular}{ccccc}
\hline Oxide (\%) & $\begin{array}{c}\text { Demolished walls } \\
\text { Material }\end{array}$ & $\begin{array}{c}\text { Waste concrete } \\
\text { (WC) }\end{array}$ & $\begin{array}{c}\text { By-pass Cement kiln } \\
\text { dust (CKD) Helwan }\end{array}$ & $\begin{array}{c}\text { Nano silica } \\
\text { (NS) }\end{array}$ \\
\hline \hline $\mathrm{SiO}_{2}$ & 76.28 & 84.09 & 4.91 & 99.90 \\
$\mathrm{Al}_{2} \mathrm{O}_{3}$ & 2.54 & 0.23 & 2.12 & 0.01 \\
$\mathrm{Fe}_{2} \mathrm{O}_{3}$ & 2.01 & 1.54 & 2.40 & 0.01 \\
$\mathrm{CaO}$ & 9.03 & 6.23 & 49.30 & 0.01 \\
$\mathrm{MgO}$ & 0.16 & 0.14 & 0.61 & 0.01 \\
$\mathrm{SO}$ & 1.31 & 0.06 & 18.50 & 0.00 \\
$\mathrm{~K}_{2} \mathrm{O}$ & 0.13 & 031 & 5.73 & 0.01 \\
$\mathrm{Na}_{2} \mathrm{O}$ & 0.2 & 0.74 & 0.32 & 0.01 \\
$\mathrm{TiO}_{2}$ & 0.02 & $/$ & 0.18 & $/$ \\
$\mathrm{MnO}_{2}$ & $/$ & $/$ & 0.01 & $/$ \\
$\mathrm{P}_{2} \mathrm{O}_{5}$ & 0.02 & $/$ & 0.08 & $/$ \\
$\mathrm{Cl}$ & $/$ & 6.59 & 8.58 & 0.02 \\
$\mathrm{LOI}$ & 7.84 & 99.94 & 6.50 & $/$ \\
$\mathrm{Total}^{-}$ & 99.56 & $/$ & 99.73 & $/$ \\
Notes & $/$ & & Free lime, CaO=15.5 & \\
\hline
\end{tabular}

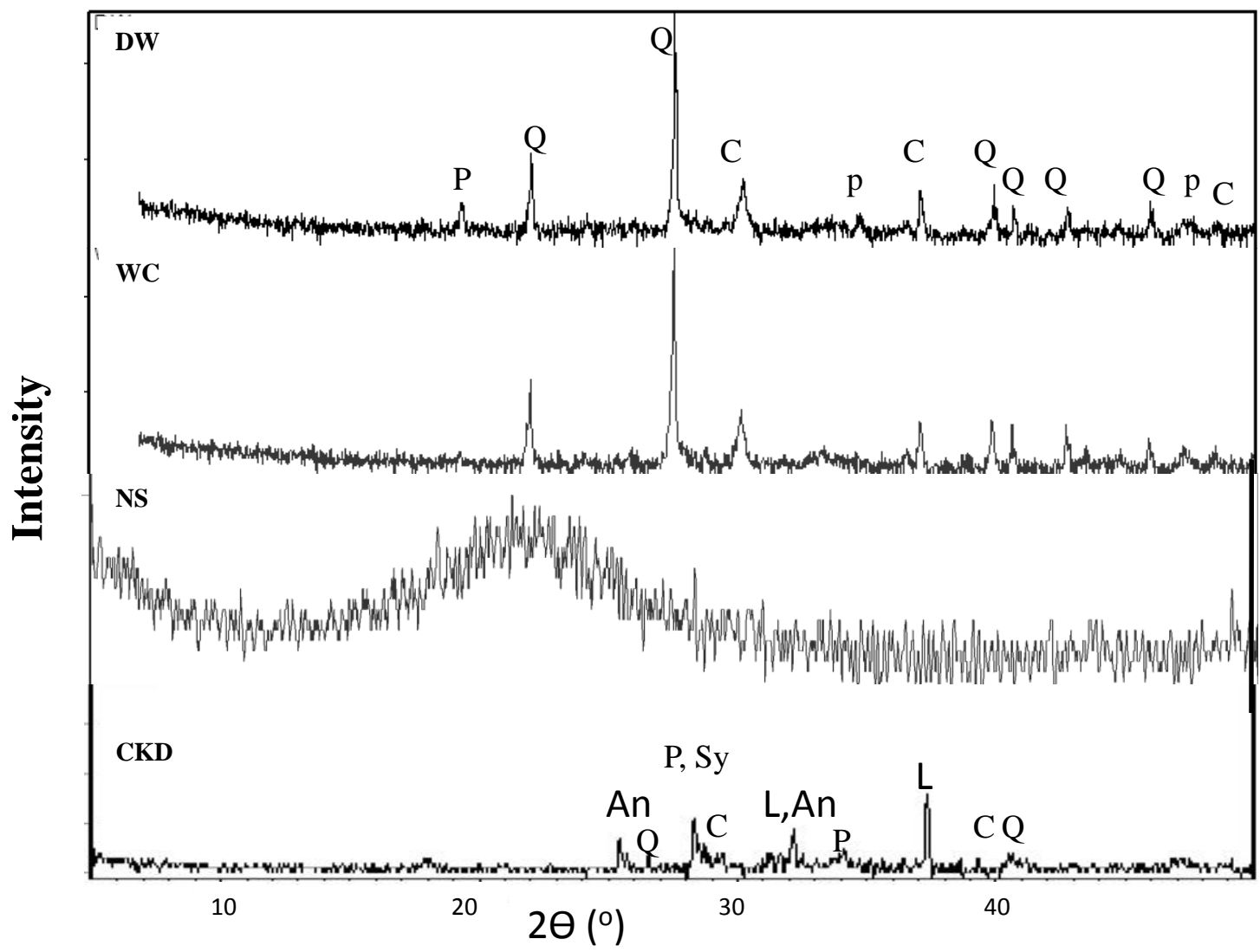

Fig 1. XRD analysis of the used raw materials.

(Q: Quartz, C: Calcite, P: Portlandite, Sy: KCl, L: Lime, An: Anhydrite $\mathrm{CaSo}_{4}$ ).

Table 2. Properties of NS.

\begin{tabular}{cc}
\hline Description & Results \\
\hline \hline Diameter $(\mathrm{nm})$ & $8-18$ \\
Purity $(\%)$ & 98 \\
Surface area $\left(\mathrm{m}^{2} / \mathrm{g}\right)$ & 240 \\
Density $\left(\mathrm{g} / \mathrm{cm}^{3}\right)$ & 0.5 \\
Molecular & $\mathrm{SiO}_{2}$ \\
Molecular weight & 60.08 \\
\hline
\end{tabular}


Transmission Electronic Microscopic (TEM) was carried out using type JEOL - JEM - 1230 of magnification up to 60000 to test the particle size of the used NS powders. Figure 2 shows the morphologies of NS, where its particles are represented by highly agglomerated clusters with size of $(40-65 \mathrm{~nm})$. Alkaline activator used is Sodium hydroxide $(\mathrm{NaOH})$ produced by SHIDO company with $99 \%$ purity for activation and formation of geopolymer constituents.

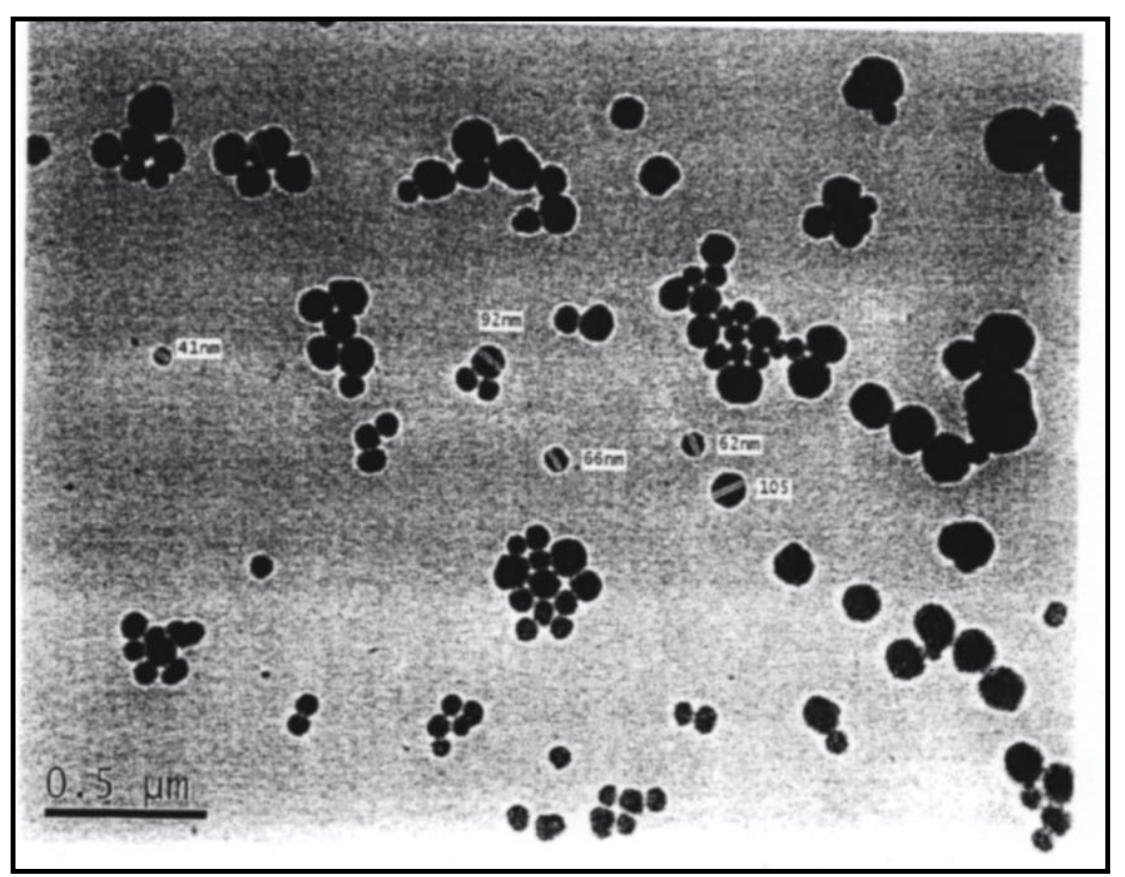

Fig 2. Transmission electron microscope of NS.

\subsection{Dispersion of NS}

NS material was first subjected for sonication using a Fritish 450 Sonifier Analog Cell Distributor for 15 min (Collins et al., 2012). Gelenium Ace 30-polycarboxylate based super- plasticizer used for NS dispersion as this Polycarboxylate based superplasticizer has been proven to be effective for NS dispersion (Senff et al., 2010). Solutions with concentration of 0, 1, 3, 5, 7 and 8-wt., \% of the used waste concrete were used to identify the effect of NS concentrations for the evaluation of its threshold ratio.

\subsection{Geopolymerization and curing}

Nano-particles are not easy to disperse uniformly due to their high surface energy. Accordingly, mixing was performed as follows:

1. Nano-SiO ${ }_{2}$ particles were stirred with $50 \%$ of the mixing water using high speed magnetic stirrer for $15 \mathrm{~min}$.

2. Geopolymer materials passing a sieve of $90 \mu \mathrm{m}$ as represented in Table 3 were hand mixed with the alkaline activator solution and with the other part of mixing water for 10 minute followed by a further 5 minute using rotary mixer and mixed at medium speed (80 rpm) for another $30 \mathrm{~s}$.

3. Gelenium Ace- 30 superplasticizer (Polycarboxylate based) were added and stirred with the mixture at high speed for additional $30 \mathrm{~s}$, followed by the previously stirred NS.

4. The mixture allowed to rest for $90 \mathrm{~s}$ and then mixed for $1 \mathrm{~min}$ at high speed.

All investigations involved the addition of $2 \mathrm{wt}$., $\% \mathrm{NaOH}$ of dry mixes. Water-binder material ratio (W/B) increases depending on the added Nano content as indicated in Table 3. The paste 
mixture was casted into $25 \times 25 \times 25 \mathrm{~mm}$ cubic-shaped moulds, vibrated for compaction and sealed with a lid to minimize any loss of evaporable water.

Table 3. Composition of the geopolymer mixes (Mass, \%).

\begin{tabular}{cccccccc}
\hline Mix N & $\begin{array}{c}\text { Waste } \\
\text { concrete } \\
\text { (WC) }\end{array}$ & $\begin{array}{c}\text { Demolished } \\
\text { walls (DW) }\end{array}$ & $\begin{array}{c}\text { Cement kiln } \\
\text { dust (CKD) }\end{array}$ & $\begin{array}{c}\text { Nano Silica } \\
\text { (NS) }\end{array}$ & W/B ratio & superplasticizer & NaOH \\
\hline C0 & 40.0 & 60 & $/$ & 0 & 0.300 & $/$ & 2 \\
C1 & 40.0 & 50 & 10 & 0 & 0.320 & $/$ & 2 \\
C2 & 40.0 & 40 & 20 & 0 & 0.334 & $/$ & 2 \\
C3 & 40.0 & 30 & 30 & 0 & 0.380 & $/$ & 2 \\
C4 & 40.0 & 20 & 40 & 0 & 0.420 & $/$ & 2 \\
C5 & 40.0 & 10 & 50 & 0 & 0.434 & $/$ & 2 \\
S0 & 40.0 & 20 & 40 & 0 & 0.360 & 1.5 & 2 \\
S2 & 39.6 & 20 & 40 & 1 & 0.360 & 1.7 & 2 \\
S3 & 38.8 & 20 & 40 & 3 & 0.370 & 1.7 & 2 \\
S4 & 38.0 & 20 & 40 & 5 & 0.380 & 2.3 & 2 \\
S5 & 37.2 & 20 & 40 & 7 & 0.400 & 2.7 & 2 \\
S6 & 36.8 & 20 & 40 & 8 & 0.420 & 3.0 & 2 \\
\hline
\end{tabular}

All mixes were left to cure undisturbed under ambient temperature $\left(23^{\circ} \mathrm{C}\right)$ for $24 \mathrm{hrs}$, demolded and then some specimens were left to be water cured under room temperature. At the end of the curing regime, the specimens were removed from their curing condition, dried well at $80^{\circ} \mathrm{C}$ for $24 \mathrm{hrs}$ then exposed to the compressive strength measurements, while the other parameters estimated by using the resulted crushed specimens.

\subsection{Methods of investigation}

Axios (PW4400) WD-XRF Sequential Spectrometer (Panalytical, Netherland) was used for Chemical analysis of the used materials. Compressive strength tests were carried out using five tones German Brüf pressing machine with a loading rate of $100 \mathrm{~kg} / \mathrm{min}$ determined according to ASTM C109M (2012). Mineralogical investigation performed by using Philips PW 1050/70 XRD

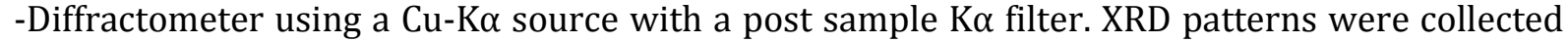
from $2 \theta=0^{\circ}$ to $50^{\circ}$. Data were identified according to the XRD software (pdf-2: database on CDRelease 2005).Particle size analysis was done using a laser scattering particle size distribution analyzer (Horiba LA-950, Kyoto, Japan). Hydration stopped by subjecting crushed specimens to stopping the solution of alcohol/acetone (1:1) using stopping solution on followed by washing with acetone as recommended by different investigators (Saikia et al., 2004; Khater, 2010) to prevent further hydration.

Transmission Electronic Microscopic (TEM) (type JEOL - JEM - 1230) used to measure the particle size of the nanomaterials. Bonding characteristics of the alkali activated specimens were analyzed using a Jasco-6100 Fourier transformed infrared spectrometer FTIR. Test sample was ground and uniformly mixed with $\mathrm{KBr}$ at a weight ratio $\mathrm{KBr}$ : specimen=200:1.The mixture, 0.20 g was pressed to a disk of $13 \mathrm{~mm}$ in diameter for analysis at $8 \mathrm{t} / \mathrm{cm}^{2}$.The wave number was ranging from 400 to $4000 \mathrm{~cm}^{-1}$ (De Vargas et al., 2014; Panias et al., 2007).

\section{Results and discussion}

\subsection{Effect of CKD on Geopolymer characterization}

FTIR spectra of 28 days cured $\left(40^{\circ} \mathrm{C}\right.$ and $100 \%$ R.H.) geopolymer specimens having various CKD content are shown in Fig. 3. Bands description are as follow: stretching vibration of $\mathrm{O}-\mathrm{H}$ bond at about $3430 \mathrm{~cm}^{-1}$, bending vibration of $\mathrm{H}-\mathrm{O}-\mathrm{H}$ bond at about $1630 \mathrm{~cm}^{-1}$, stretching vibration of $\mathrm{CO}_{2}$ located at about $1430 \mathrm{~cm}^{-1}$, asymmetric stretching vibration (T-O-Si) at about $1100 \mathrm{~cm}^{-1}$ 
where $\mathrm{T}=\mathrm{Si}$ or $\mathrm{Al}$, symmetric stretching vibration of $\mathrm{CO}_{2}$ at about $870 \mathrm{~cm}^{-1}$, symmetric stretching vibration ( $\mathrm{Si}-0-\mathrm{Si}$ ) attributed to $\alpha$-quartz at about $797 \mathrm{~cm}^{-1}$, symmetric stretching vibration (Al -O-Si) between778-781 $\mathrm{cm}^{-1}$, symmetric stretching vibration ( $\mathrm{Si}-\mathrm{O}-\mathrm{Si}$ and $\mathrm{Al}-\mathrm{O}-\mathrm{Si}$ ) in the region $676-688 \mathrm{~cm}^{-1}$ and bending vibration (Si-O-Si and $\mathrm{O}-\mathrm{Si}-0$ ) in the region $410-460 \mathrm{~cm}^{-1}$.

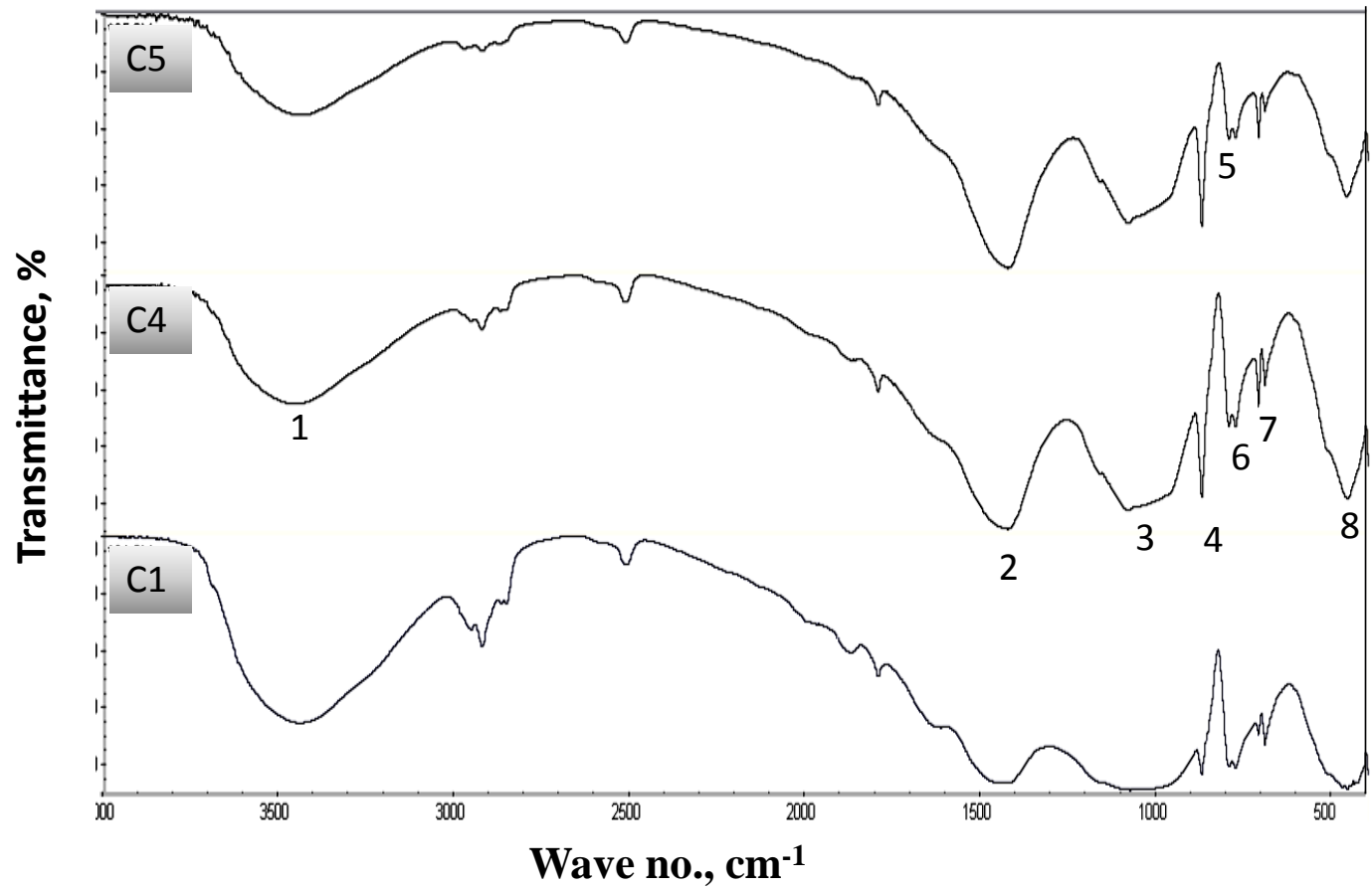

Fig 3. FTIR spectra of 28 days cured $\left(\hat{38}{ }^{\circ} \dot{\mathrm{C}}\right.$ and $100 \%$ R.H.) geopolymer specimens having various CKD content, where: $\mathrm{C} 1$ has $10 \% \mathrm{CKD}$, C4 has $40 \% \mathrm{CKD}$, and C5 has $50 \%$ CKD.

1: Stretching vibration of $\mathrm{O}-\mathrm{H}$ bond, 2: Bending vibrations of $(\mathrm{HOH}), 3$ : Asymmetric stretching vibration (T-O-Si), 4: Symmetric stretching vibration of $\mathrm{CO}_{2}, 5$ : Symmetric stretching vibration (SI-O-SI) attributed to $\alpha$-quartz, 6: Symmetric stretching vibration (AlO-Si), 7: Symmetric stretching vibration (Si-O-Si and Al-O-Si), 8: Bending vibration (Si-O-Si and O-Si-O).

The pattern indicates the growth and the broadness of the main asymmetric band with CKD increase up to $40 \%$, and then decreases with further increase. The increase in the band indicates the increased content of N-A-S-H gel which has a positive effect on strength increase. This illustrated the aluminosilicate polycondensation reactions with CKD addition up to 40\%, resulting in growth of $\mathrm{N}-\mathrm{A}-\mathrm{S}-\mathrm{H}$ gel, which contributes to an increase in mechanical properties of the resulting structure.

Bands at about $797 \mathrm{~cm}^{-1}$ decreases with the CKD increase indicating the increased dissolution in $\alpha$-quartz of the reacting raw materials, but the contribution of the resulting dissolved silica lowered with CKD more than $40 \%$ which favoring the mononuclear formation than oligomerization and polymerization where the increased alkali contents consumes the surface species ( $>\mathrm{T}-\mathrm{OH}$ and $>\mathrm{T}-\mathrm{O}-$ ), where the bonding between insoluble solid particles and the geopolymeric framework takes place. Thus, the resulted geopolymeric materials will have low mechanical characteristics (Panias et al., 2007; Baes et al., 1976).

Bands at about 777 and $694 \mathrm{~cm}^{-1}$ for symmetric vibration band of (Al-O-Si) as well as the symmetric band of (Si-O-Si and $\mathrm{Al}-\mathrm{O}-\mathrm{Si}$ ) are directly proportional to the asymmetric vibration band giving an indication about the increased dissolution and polymerization of aluminosilicate gel with CKD up to $40 \%$.

The appearance of bands in the regions of $1430 \mathrm{~cm}^{-1}(\nu \mathrm{C}-0)$, and $867 \mathrm{~cm}^{-1}(\delta \mathrm{C}-0)$ are typical of $\mathrm{CO}_{3}{ }^{2-}$ vibrational groups, present in inorganic carbonates (Lodeiro et al., 2010), whilst the increased intensity of carbonate peaks with the increase of CKD arises from the increased intensity of carbonate within CKD in addiction to carbonation of the free alkalies lies within CKD. 
Figure 4 shows the 28 days compressive strength of geopolymer mixes cured at $40^{\circ} \mathrm{C}$ and $100 \%$ R.H. It is found that, the compressive strength of geopolymer specimens increase with CKD up to $40 \%$ then decrease with further CKD increase, giving an increased mechanical strength than the control by $89.9,112.6,143.4$ and $172 \%$ for $10,20,30$ and $40 \%$, respectively, while further increase in CKD up to 50\% leads to increase in the alkali content in the matrix and so efflorescence occurs, however strength still higher than the control one by $67.1 \%$

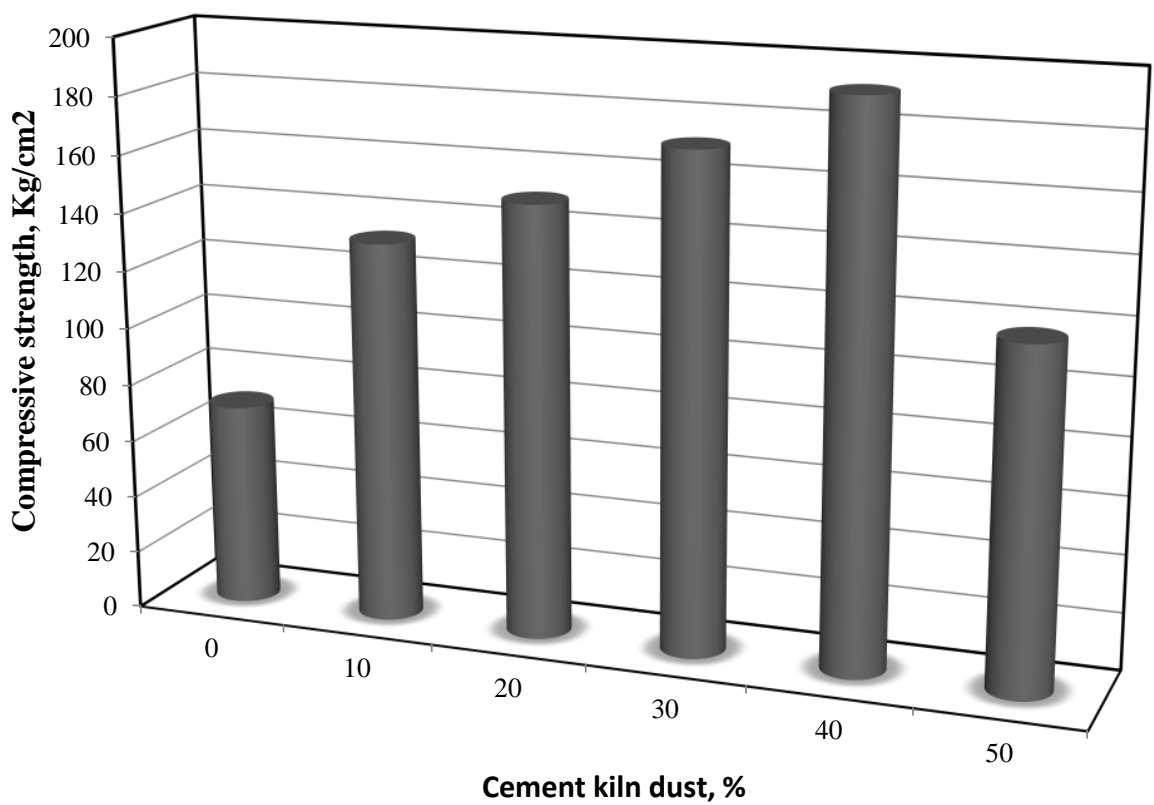

Fig 4. Compressive strength of 28 days cured alkali activated geopolymer specimens having various ratios of CKD.

This can be explained by the high alkalis that lie within CKD lead to increase in $\mathrm{pH}$ of the medium and so the degree of polymerization of the resulting product. While further increase in CKD results in an extra alkalis increase which will negatively affect the reaction by terminating the geopolymer chains and also favor the reverse reaction for monomer formation and consuming the surface structure as mentioned before. This can illustrated well from the previously showed FTIR figure where the increased broadness and intensity of the main asymmetric peak (T-O-Si), as well as the symmetric peak of (Al-O-Si) when using $40 \% \mathrm{CKD}$ emphasize the growth of N-A-S-H gel, which contributes to the increase in mechanical properties of the resulting structure with CKD addition up to $40 \%$, while the reverse effect of alkali comes clear as these band lowered with increased CKD content (Baes et al., 1976).

\subsection{Effect of Nano-silica on Geopolymer characterization}

XRD pattern of alkali-activated geopolymer mix admixed with Gelenium Ace superplasticizer without NS and cured at $38^{\circ} \mathrm{C}$ and $100 \%$ R.H., from 1 up to 180 days is shown in Figure 5. The pattern illustrate a broad band in the region of $6^{\circ}$ to $10^{\circ} 2 \theta$ for aluminosilicate gel and broad bands in the region of $17^{\circ}$ to $35^{\circ} 2 \theta$ characterizing glassy phase of geopolymer constituents. These two regions are considered as a vital role in geopolymer characterization, where any increase in these regions will be reflected on the performance and efficiency of the resulting geopolymer gel. CSH content increased with the increase of curing time as indicated from the increased broadness at $29.4^{\circ}$ that results from the interaction of freely dissolved silica with $\mathrm{Ca}$ species in the matrix forming $\mathrm{CSH}$, which accumulate in the open pores and transformed into crystalline form at the later curing ages, this will be in accordance with the consumption of the free portlandite content beyond 7days. However, Aluminate phases that formed at early ages diminished with time as it dissolved into free alumina by alkaline effect and incorporated in the 3D geopolymer network, which emphasized by the increased hump in the region between 17 $35^{\circ} 2 \theta$. 


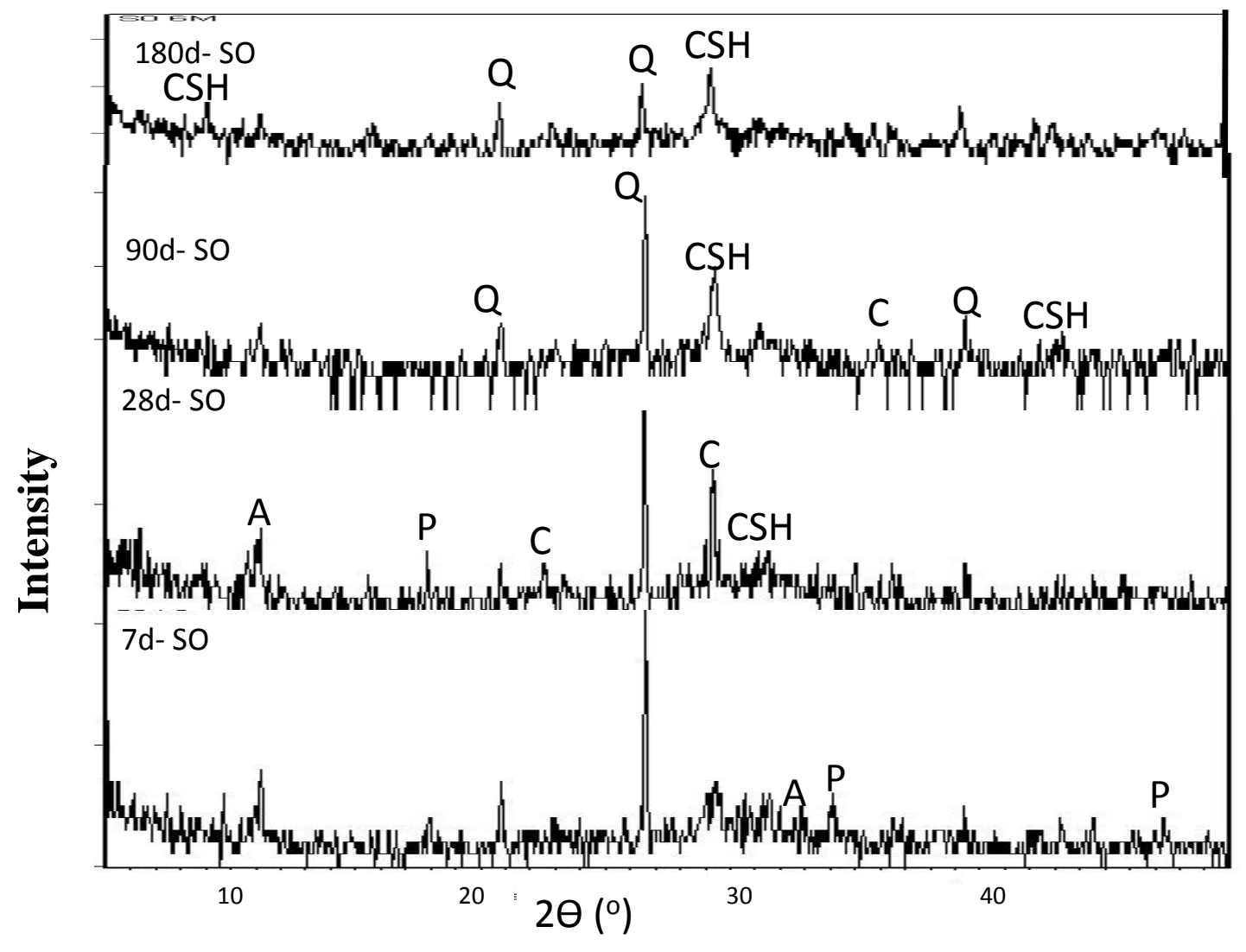

Fig 5. XRD pattern of geopolymer mix without NS at different curing ages.

(Q: Quartz, A: $\mathrm{C}_{4} \mathrm{AH}_{13}$, C: Calcite, CSH: Calcium silicate hydrate)

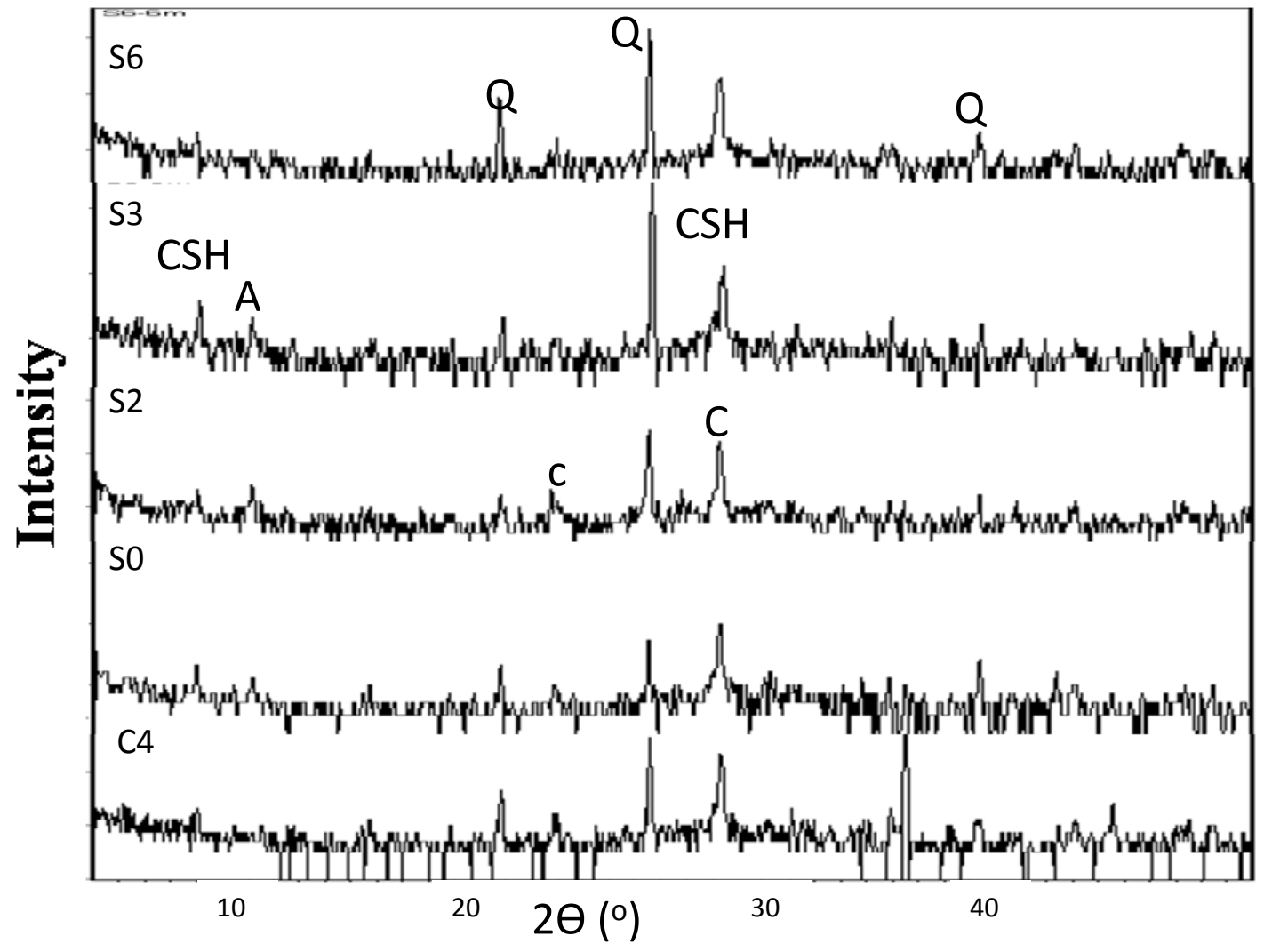

Fig 6. XRD pattern of 180 days geopolymer mixes having various NS content.

(Q: Quartz, A: $\mathrm{C}_{4} \mathrm{AH}_{13}$, C: Calcite, CSH: Calcium silicate hydrate) 
Addition of NS results in the increase in the $\mathrm{CSH}$ phases at $29.4^{\circ}$ up to $3 \%$, then decreases with further nanomaterials increase as illustrated in 180 days XRD spectra Figure 6 . Where the dissolved Ca species react with the amorphous nanomaterials forming CSH that acts as a nucleating sites for formation and accumulation of dissolved species leading to a rapid hardening, forming a fine and homogeneous structure (Khater, 2012; Khater, 2013-b).

FTIR spectra of the control mix without NS and admixed with Gelenium Ace Superplasticizer for 90 days are shown in Fig. 7. The spectra showed the growth of the main asymmetric band at about $950 \mathrm{~cm}^{-1}$ with curing time reflecting the growth of the three dimensional geopolymer network (N-A-S-H gel) with time which accompanied by the decrease in the shoulder that lies at about $1100 \mathrm{~cm}^{-1}$ for asymmetric vibration of non-dissolved silica from the reacting materials with time; reflecting the dissolution of the reacting materials and formation of geopolymer chains (Panias et al., 2007). There is also shoulder at about $3600 \mathrm{~cm}^{-1}$ for portlandite which decrease with time, forming the binding CSH phases which is in accordance with XRD pattern in Figure (5). The spectra showed also the decrease of the carbonate content at about 1430, 870 $\mathrm{cm}^{-1}$ with time where the resulted geopolymer structures fill most of the open pores and mostly all the alkaline activators consumed in the geopolymer formation, where the free alkalis in the medium are susceptible to carbonation and results in formation of trona $\left(\mathrm{Na}_{3} \mathrm{H}\left(\mathrm{CO}_{3}\right)_{2} \cdot 2 \mathrm{H}_{2} \mathrm{O}\right)$ and natron $\left(\mathrm{Na}_{2} \mathrm{CO}_{3} \cdot 10 \mathrm{H}_{2} \mathrm{O}\right)$.

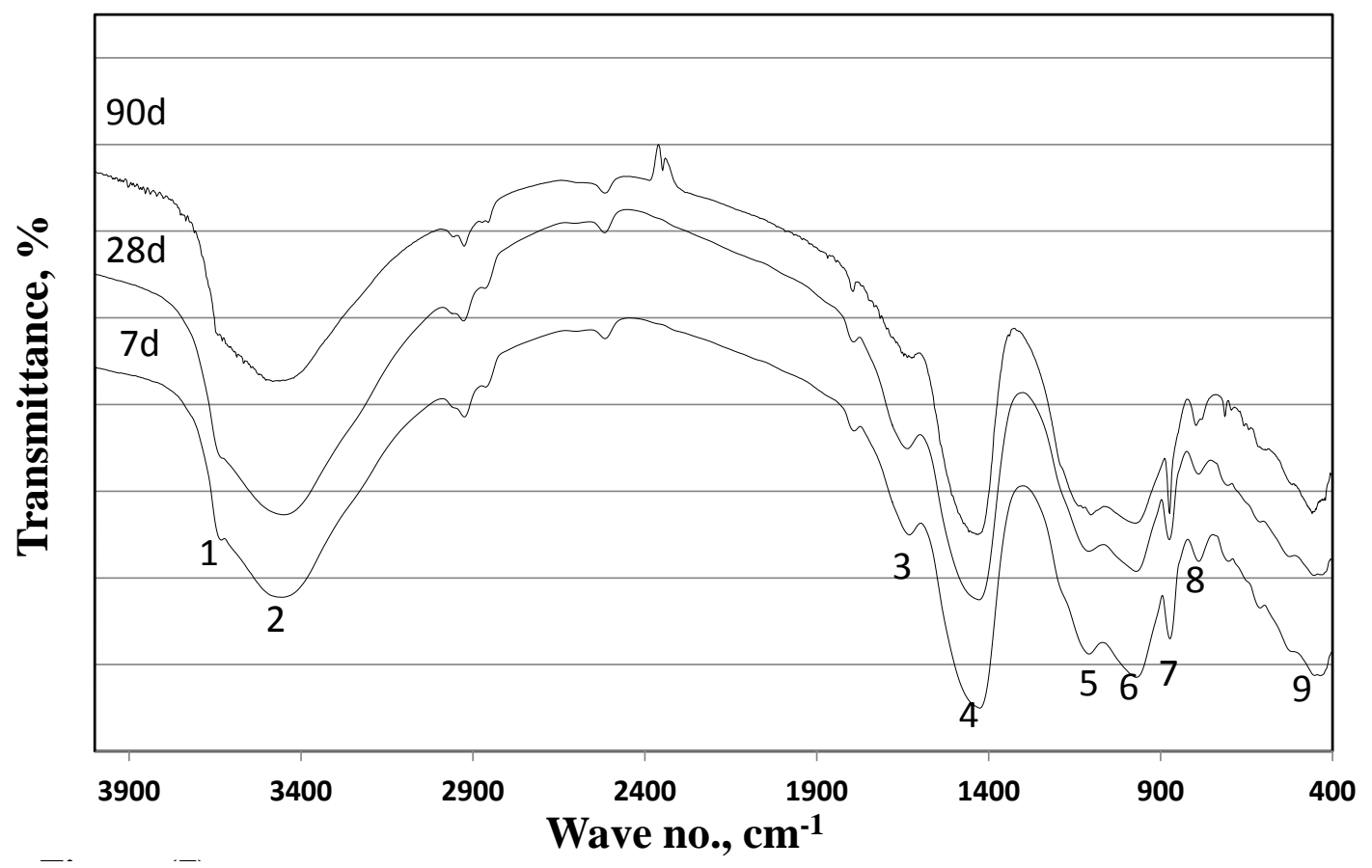

Fig 7. FTIR spectra of control geopolymer mix without NS, admixed with superplasticizer, cured $(40 \%$ and $100 \%$ R.H.) at various curing times.

(1,2: Stretching vibration of $\mathrm{O}-\mathrm{H}$ bond, 3: Bending vibrations of $(\mathrm{HOH})$, 4: Stretching vibration of $\mathrm{CO}_{2}$, 5: Asymmetric stretching vibration (SI-O-SI), 6: Asymmetric stretching vibration (T-O-Si), 7: Symmetric stretching vibration of $\mathrm{CO}_{2}$, 8: Symmetric stretching vibration of (Si-O-Si) attributed to $\alpha$-quartz, 9: Bending vibration (Si-O-Si and O-Si-O)).

FTIR spectra of geopolymer mixes having various ratios of NS cured up to 90 and 180 days are shown in Figures 8 and 9 respectively. Figure 8 showed the growth of the main asymmetric band at about $950 \mathrm{~cm}^{-1}$ and decreased intensity of asymmetric shoulder of Si-O-Si related to nonsolubilized quartz particles in raw materials with the increased dose of NS up to 3\% then this asymmetric band increased again. As mentioned before, the increased intensity of asymmetric peak give an indication about the propagation and polymerization of the aluminosilicate network as the NS acts as a seeding agent for geopolymer accumulation and precipitation while further increase leads to the agglomeration of the NS leading to the formation of heterogeneous 
structure filled with many pores and more prone to carbonation. This confirms the decreased intensity of carbonate band with NS up to $3 \%$ then increased again with further increase. The spectra illustrate also the enhanced effect of superplasticizer on the Geopolymerization reaction as come clear from the asymmetric band of T-O-Si and the noticeable increase in the intensity of asymmetric Si-O-Si than admixed with superplasticizer, this will reflected positively on the mechanical characteristics of the resulting product.

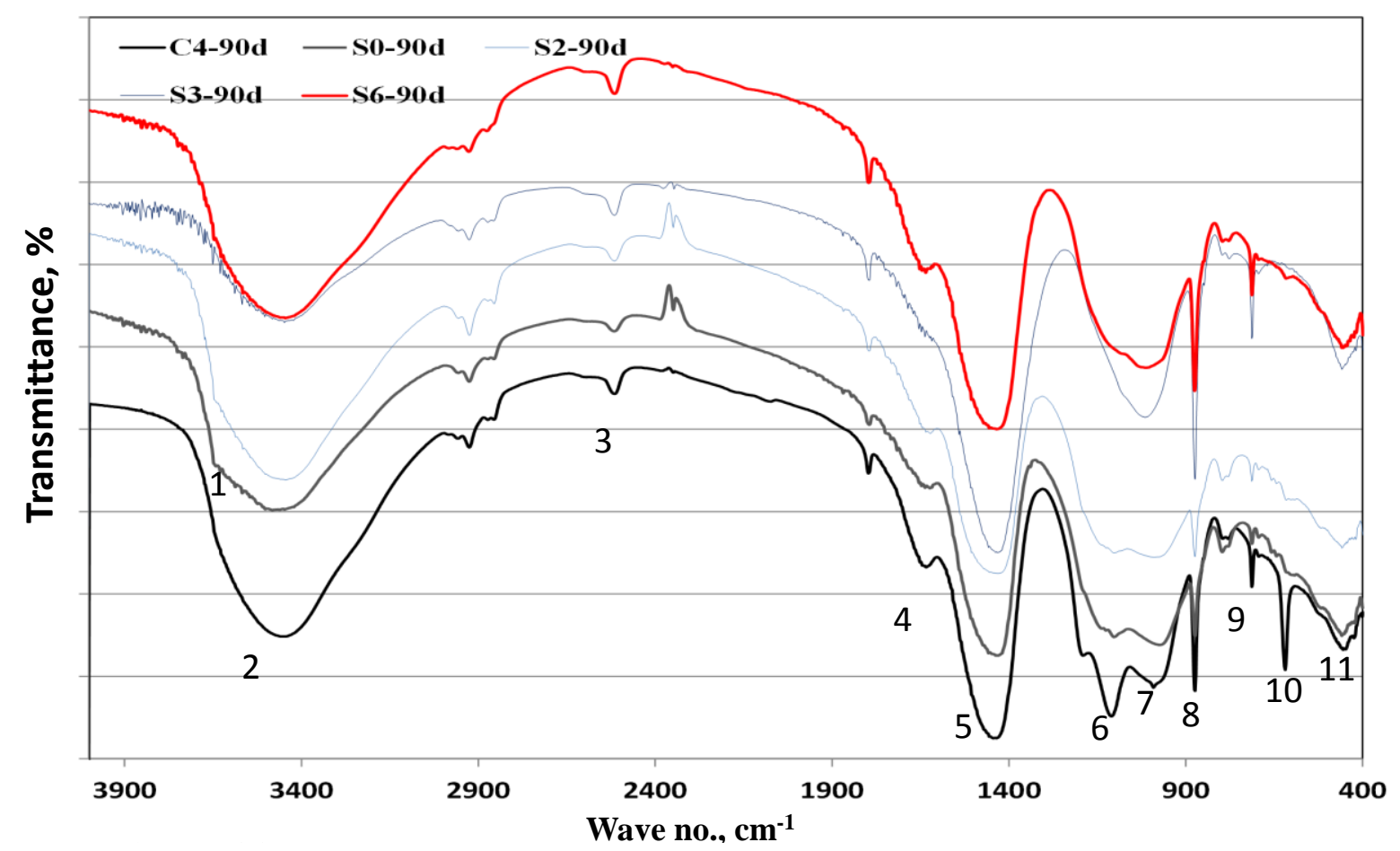

Fig 8. FTIR spectra of 90 days cured (40\% and $100 \%$ R.H.) geopolymer specimens having various NS content.

1,2,3: Stretching vibration of $\mathrm{O}-\mathrm{H}$ bond, 4: Bending vibrations of $(\mathrm{HOH}), 5$ : Stretching vibration of $\mathrm{CO}_{2}, 6$ : Asymmetric stretching vibration (Si-O-Si), 7: Asymmetric stretching vibration (T-O-Si), 8: Symmetric stretching vibration of $\mathrm{CO}_{2}$, 9,10: Symmetric stretching vibration (Si-O-Si and Al-O-Si), 11: Bending vibration (Si-O-Si and O-Si-O).

Further increase in curing time up to 180 days (Figure 9) results in an increased enhancement in the broadness of the main T-O-Si asymmetric band and decrease in the intensity of nonsolubilized shoulder next to the previous band with the same sequence of the latter figure, which may be due to the increased dissolution of the reacting materials with time and incorporating in the formation of the geopolymer network (Lodeiro et al., 2010). The spectra showed also the decrease in the broadness and intensity of carbonate bands at about $1430,870 \mathrm{~cm}^{-1}$ with NS addition as the seeding effect of Nano materials leaves little pores in the matrix susceptible to carbonation and so good homogeneity in the matrix, while the agglomeration of higher dose of NS (>3\%) results in the increased porosity in the medium and increased carbonation depth.

Compressive strengths of geopolymer mixes that admixed with superplasticizer and that not admixed, cured up to 180 days are shown in Fig.10. The strength pattern illustrates the presence of gap in strength values between specimens admixed with SP and those not admixed and this gap increases with time up to 180 days. This gap can be explained by the good homogeneity in the matrix structure, better rearrangement in the geopolymer network and good increased yield of the polymerization and precipitation. These facts confirmed by the increased content of N-A$\mathrm{S}$ - $\mathrm{H}$ gel indicated from the asymmetric band at about $950 \mathrm{~cm}^{-1}$ (Figures 8,9 ) and also from the increased broadness of CSH peak in XRD pattern (Figure 6). 


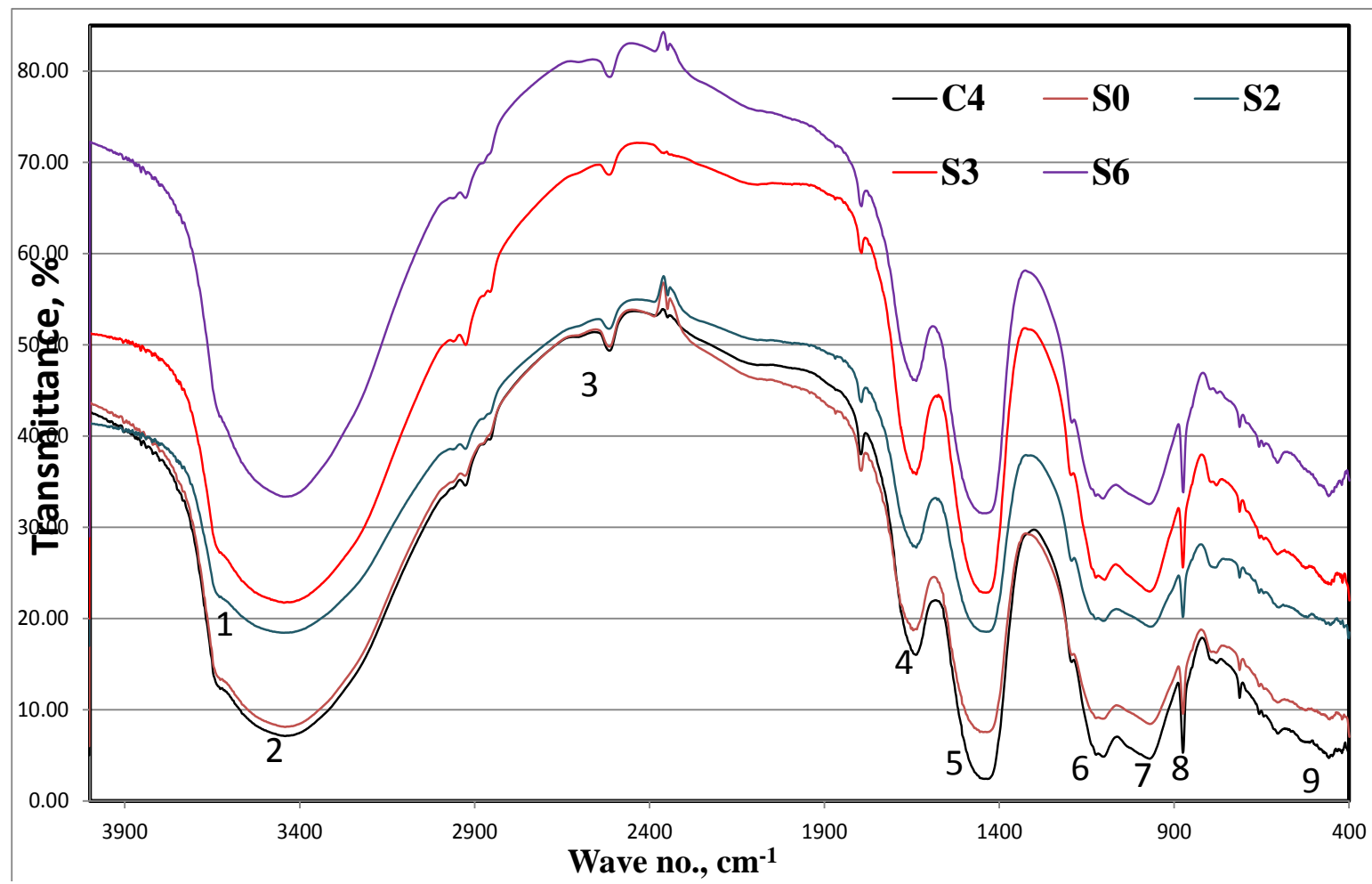

Fig 9. FTIR spectra of 180 days cured ( $40 \%$ and $100 \%$ R.H.) geopolymer specimens having various NS content.

1,2,3: Stretching vibration of $\mathrm{O}-\mathrm{H}$ bond, 4: Bending vibrations of $(\mathrm{HOH}), 5$ : Stretching vibration of $\mathrm{CO}_{2}, 6$ : Asymmetric stretching vibration (Si-O-Si), 7: Asymmetric stretching vibration (T-O-Si), 8: Symmetric stretching vibration of $\mathrm{CO}_{2}$, 9: Bending vibration (Si-OSi and O-Si-O).

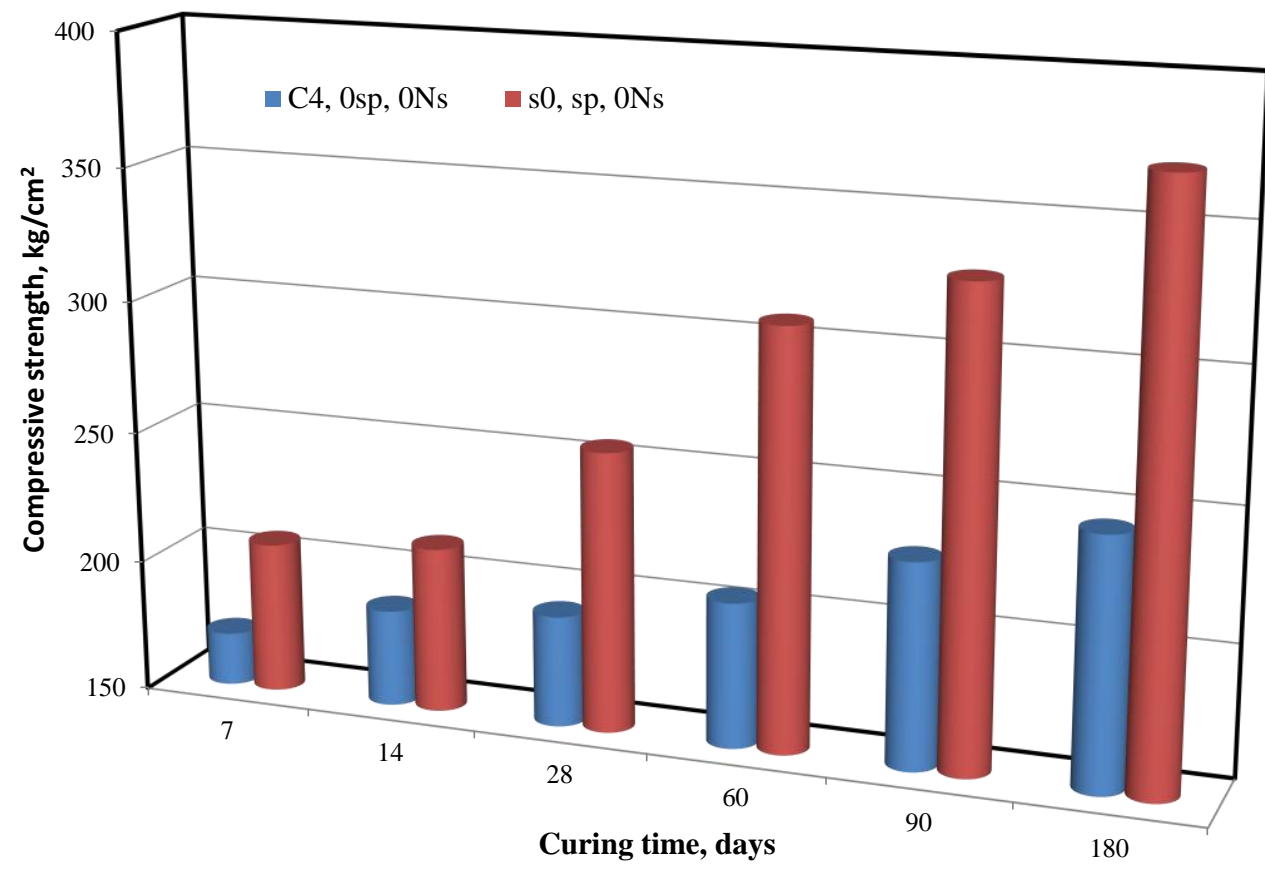

Fig 10. Comparing the compressive strength of alkali activated geopolymer specimens admixed and those not admixed with superplasticizer. 
Compressive strengths of geopolymer mixes that contain various ratios of NS from 0 up to $7 \%$ cured up to 180 days are shown in Fig. 11. The strength pattern illustrates the increase in strength of all mixes with curing time as a result of hydration progress forming CSH as well as geopolymer formation leading to a fine and homogeneous structure; where NS has a specific surface of $160 \mathrm{~m}^{2} / \mathrm{g}$, so the reaction between $\mathrm{SiO}_{2}$ and free $\mathrm{Ca}(\mathrm{OH})_{2}$ shows differences between the geopolymer precursor carrying free lime and NS is going in quick pattern rate where NS having many unsaturated bonds $\mathrm{Si}-\mathrm{O}$ and $\mathrm{Si}$ in the surface, the reaction process between $\mathrm{SiO}_{2}$ and $\mathrm{Ca}(\mathrm{OH})_{2}$ may be as follows:

$=\mathrm{Si}-\mathrm{O}-+\mathrm{H}-\mathrm{OH} \rightarrow=\mathrm{Si}-\mathrm{OH}$----react quickly

$=\mathrm{Si}-+\mathrm{OH} \rightarrow=\mathrm{Si}-\mathrm{OH}----$ react quickly

$=\mathrm{Si}-\mathrm{OH}+\mathrm{Ca}(\mathrm{OH})_{2} \rightarrow \mathrm{C}-\mathrm{S}-\mathrm{H}$

Furthermore, increasing NS content up 3\% leads to enhancement in seeding nucleation and possess an additional nucleation sites for the geopolymer precursors formation. It is obvious that increase in the NS content beyond 3\% did not change compressive strength significantly. It is found that large amounts of NS decrease the compressive strength of the composites instead of improving it. As the increased content of NS leads to difficulty in dispersing uniformly ,therefore a weak zone in the form of voids is formed, consequently the homogeneous hydrated microstructure cannot be formed and a lower strength will be probable ( $\mathrm{Li}$ and $\mathrm{Ou}, 2004$ ). Furthermore, with increasing the NS content up to 3\%, geopolymer paste strength increased. For example, compared with control sample, the strengths of 3\%NS increased by $39.95 \%$, $43.3 \%, 42.6 \%$ and $43.1 \%$ at ages of 7 day, 28 days, 90 days and 180 days, respectively, while using $5 \%$ NS leads to strength loss by $-4.2,-0.03,9.23$ and $-0.94 \%$ at ages of 7 day, 28 days, 90 days and 180 days, respectively.

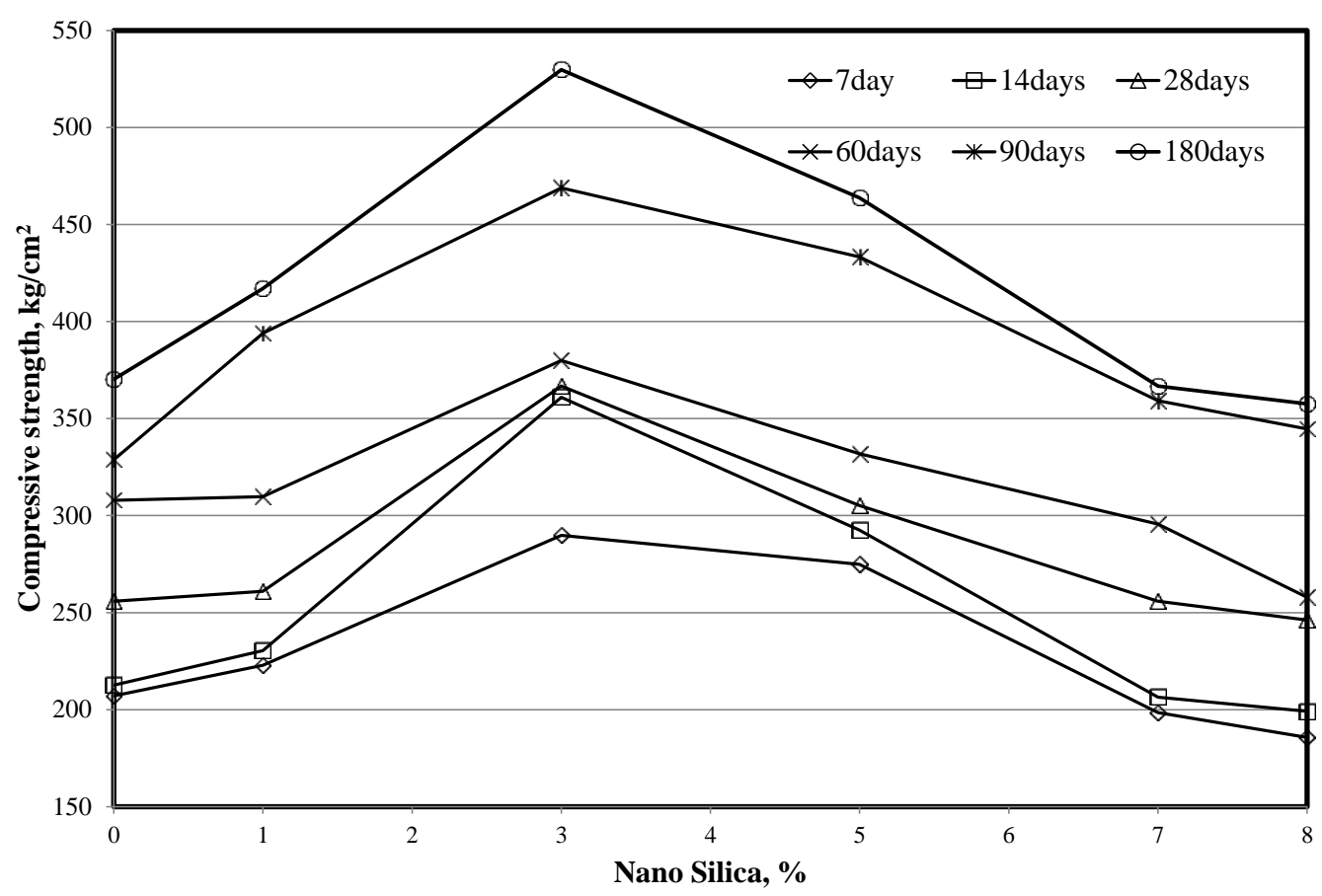

Fig 11. Compressive strength of alkali activated geopolymer specimens doped with various doses of NS.

The trend of variation of compressive strength coincides with the XRD data, FTIR spectrum observations Figures 8 and 9, where the amorphous content of geopolymer materials increased with increasing NS content - as indicated from the increased intensity of main asymmetric T-O-Si band- as it forms more precipitation sites for geopolymer accumulation and precipitation when it interacts with free lime in the medium, forming CSH. Further increase in NS leads to insufficient wetting of the medium that hinder the propagation of geopolymer chains and so 
weaken its mechanical properties; as indicated from the increased carbonate content due to the increased weak zone with increased agglomeration of NS and so decrease of the intensity of amorphous band N-A-S-H as illustrated previously.

\section{Conclusion}

1- Cement kiln dust (CKD) has high alkalis content and free lime that can efficiently be utilized in the activation of geopolymer precursors.

2- Alkaline activation of aluminosilicate wastes in addition to alkalis lies within the industrial cement kiln dust which can possess ultra-activation results in the production of environmentally friendly cementing materials that can be applied in various building purposes.

3- Uses of CKD for activation of aluminosilicate from demolition wastes can be effectively used up to $40 \%$, while further increase leads to increase in the free alkali that can be susceptible to carbonation.

4- CKD addition to alkali activated aluminosilicate materials results in better enhancement in the Geopolymerization process up to $40 \%$, giving increased mechanical strength than the control by $172 \%$, while further increase leads to increase in the alkali content in the matrix and so efflorescence occurs, however strength still higher than the control one by $67.1 \%$

5- Using nano silica (NS) to alkali activated geopolymer specimens' increase and offers an extra nucleation sites for geopolymer formation and accumulation.

6- Adding NS results in the enhancement in the mechanical and functional characterization of the resulting product up to $3 \%$, whereas further increase results in agglomeration and weakening in the mechanical characteristics.

\section{References}

Aiu, M., Huang, C. P. (2006). The chemistry and physics of nano-cement.Loyola Marymount University, NSF-REU University of Delaware.

ASTM C109M-12 (2012). Standard Test Method for Compressive Strength of Hydraulic Cement Mortars.

Baes, C. F., Mesmer, R. E. The Hydrolysis of Cations, John Willey \& Sons, New York, 1976.

Collins, F., Lambert, J., Duan, W. H. (2012). The influences of admixtures on the dispersion, workability, and strength of carbon nanotube-OPC paste mixtures. Cement and Concrete Composites, 34(2), 201-207.

De Vargas, A. S., Dal Molin, D. C., Masuero, Â. B., Vilela, A. C., Castro-Gomes, J., De Gutierrez, R. M. (2014). Strength development of alkali-activated fly ash produced with combined $\mathrm{NaOH}$ and $\mathrm{Ca}(\mathrm{OH})_{2}$ activators. Cement and Concrete Composites, 53, 341-349.

Duxson, P., Fernández-Jiménez, A., Provis, J. L., Lukey, G. C., Palomo, A., Van Deventer, J. S. J. (2007-a). Geopolymer technology: the current state of the art. Journal of Materials Science, 42(9), 2917-2933.

Duxson, P., Provis, J. L., Lukey, G. C., Van Deventer, J. S. (2007-b). The role of inorganic polymer technology in the development of 'green concrete'. Cement and Concrete Research, 37(12), 1590-1597.

Duxson, P. S. W. M., Mallicoat, S. W., Lukey, G. C., Kriven, W. M., Van Deventer, J. S. J. (2007). The effect of alkali and $\mathrm{Si} / \mathrm{Al}$ ratio on the development of mechanical properties of metakaolin-based geopolymers. Colloids and Surfaces A: Physicochemical and Engineering Aspects, 292(1), 8-20.

Fernández-Jiménez, A., Palomo, A. (2005). Composition and microstructure of alkali activated fly ash binder: effect of the activator. Cement and concrete research, 35(10), 1984-1992.

Fernández-Jiménez, A., Palomo, A., Criado, M. (2006). Alkali activated fly ash binders. A comparative study between sodium and potassium activators. Materiales de Construcción, 56(281), 51-65.

Hajimohammadi, A., Provis, J. L., Van Deventer, J. S. (2008). One-part geopolymer mixes from geothermal silica and sodium aluminate. Industrial \& Engineering Chemistry Research, 47(23), 9396-9405. 
Khater, H. M. (2010). Influence of metakaolin on resistivity of cement mortar to magnesium chloride solution. Ceramics-Silikáty, 54(4), 325-333.

Khater, H. M. (2012). Effect of calcium on geopolymerization of aluminosilicate wastes. Journal of Materials in Civil Engineering, 24(1), 92-101.

Khater, H. M. (2013-a). Effect of cement kiln dust on geopolymer composition and its resistance to sulfate attack. Green Materials, 1(1), 36-46.

Khater, H. M. (2013-b). Effect of silica fume on the characterization of the geopolymer materials. International Journal of Advanced Structural Engineering (IJASE), 5(1), 1-10.

Li, H., Xiao, H. G., Ou, J. P. (2004). A study on mechanical and pressure-sensitive properties of cement mortar with nanophase materials. Cement and Concrete research, 34(3), 435-438.

Li, H., Xiao, H. G., Yuan, J., Ou, J. (2004). Microstructure of cement mortar with nano-particles. Composites Part B: Engineering, 35(2), 185-189.

Lodeiro, I. G., Fernández-Jimenez, A., Palomo, A., Macphee, D. E. (2010). Effect on fresh CSH gels of the simultaneous addition of alkali and aluminium. Cement and Concrete Research, 40(1), 27-32.

McCormick, A. V., Bell, A. T. (1989). The solution chemistry of zeolite precursors. Catalysis ReviewsScience and Engineering, 31(1-2), 97-127.

Mitchell, D. R. G., Hinczak, I., Day, R. A. (1998). Interaction of silica fume with calcium hydroxide solutions and hydrated cement pastes. Cement and Concrete Research, 28(11), 1571-1584.

Panias, D., Giannopoulou, I. P., Perraki, T. (2007). Effect of synthesis parameters on the mechanical properties of fly ash-based geopolymers. Colloids and Surfaces A: Physicochemical and Engineering Aspects, 301(1), 246-254.

Papadakis, V. G. (1999). Experimental investigation and theoretical modeling of silica fume activity in concrete. Cement and Concrete Research, 29(1), 79-86.

Phair, J. W., Van Deventer, J. S. J. (2001). Effect of silicate activator pH on the leaching and material characteristics of waste-based inorganic polymers. Minerals Engineering, 14(3), 289-304.

Provis, J. L. (2009). Activating solution chemistry for geopolymers. Geopolymers: Structures, Processing, Properties and Industrial Applications, Wood head Publishing, Abingdon UK, pp: 50-71.

Richardson, I. G. (2000). The nature of the hydration products in hardened cement pastes. Cement and Concrete Composites, 22(2), 97-113.

Saikia, N., Usami, A., Kato, S., Kojima, T. (2004). Hydration behaviour of ecocement in presence of metakaolin. Resource Progressing Journal, 51(1), 35-41.

Senff, L., Hotza, D., Repette, W. L., Ferreira, V. M., Labrincha, J. A. (2010). Effect of nanosilica and microsilica on microstructure and hardened properties of cement pastes and mortars. Advances in Applied Ceramics, 109(2), 104-110.

Taylor, H. F. W. (1993). Nanostructure of C-S-H: Current status. Advanced cement based materials, 1(1), 38-46.

Van Jaarsveld, J. G. S., Van Deventer, J. S. J. (1999). Effect of the alkali metal activator on the properties of fly ash-based geopolymers. Industrial \& Engineering Chemistry Research, 38(10), 3932-3941.

Yang, K. H., Song, J. K. (2009). Workability loss and compressive strength development of cementless mortars activated by combination of sodium silicate and sodium hydroxide. Journal of Materials in Civil Engineering, 21(3), 119-127.

Yang, K. H., Song, J. K., Ashour, A. F., Lee, E. T. (2008). Properties of cementless mortars activated by sodium silicate. Construction and Building Materials, 22(9), 1981-1989.

Zhang, X., Chang, W., Zhang, T., Ong, C. K. (2000). Nanostructure of calcium silicate hydrate gels in cement paste. Journal of the American Ceramic Society, 83(10), 2600-2604. 